\title{
ANALISIS IMAGE NOISE DAN NILAI DOSIS RADIASI PENGGUNAAN APLIKASI CARE DOSE 4D DAN NON CARE DOSE 4D PADA PESAWAT MSCT SIEMENS
}

\section{ANALYSIS IMAGE NOISE AND RADIATION DOSE VALUE OF APPLICATION USING CARE DOSE 4D AND NON CARE DOSE 4D IN SIEMENS MSCT}

\author{
Tito Aditya Resmana ${ }^{1)}$, Darmini ${ }^{2)}$, Sigit Wijokongko ${ }^{3)}$ \\ ${ }^{1)}$ Mardi Rahayu Kudus Hospital \\ ${ }^{2)}$ Health Polytechnics of Semarang-Indonesia \\ ${ }^{3)}$ Tugurejo Semarang Hospital \\ Author Mail : aatitoaditya@gmail.com
}

\begin{abstract}
Background : One effective technique is contained in a CT Scan to decrease the amount of radiation dose that is received in the use of automatic exposure control (AEC). AEC system of Siemens equipment is called Care Dose 4D. The research is based on unused of the application Care Dose 4D on CT Scan Imaging. The purpose of the research is to determine the differences of image noise and the differences of radiation doses (CTDI) using care dose 4D and Non Care Dose 4D in Siemens MSCT.

Methods :The research was quantitative study with experimental approaches that is tested on four water phantom size type. Analysts data is done by statistical tests of Paired T-Test Samples to test the hypothesis and the level difference image information. In this statistical analysis is determined the level of confidence (level of Significance) with a value of $\alpha=0.05$.

Results : On the using of Nasopharing protocol for children with $130 \mathrm{kV}$ and $130 \mathrm{mAs}$ parameters, using of Care Dose 4D has ability to decrease the image noise value is compared with non Care Dose 4D application. While the adult Nasopharing protocol with $130 \mathrm{kV}$ and 220 mAs parameters, Care Dose 4D doesn't provide enough impact in the reduction of image noise value if compared with conventional techniques or without using Care Dose 4D applications. Using of children nasopharing protocol application Care Dose 4D even increase radiation closes high enough value in CTDI vol that is 5,03 mGy, but using Nasopharing Care Dose 4D applications for adult can decrease radiation doses high enough value in CTDIvol, that is $2,64 \mathrm{mGy}$.

Conclusion : On the use of children nasopharing protocol application Care Dose 4D even increase radiation closes high enough value in CTDI vol that is 5,03 mGy, while the adult Nasopharing using Care Dose 4D applications can decrease radiation doses high enough value in CTDIvol, that is 2,64 mGy.
\end{abstract}

Keywords: Image Noise, Radiation Dose, Care Dose 4D, Non Care Dose 4D

\section{PENDAHULUAN}

Computed Tomography (CT) merupakan salah satu teknik pemeriksaan radiologi yang digunakan untuk menggambarkan struktur internal tubuh secara potongan demi potongan. Pengembangan teknologi CT Scan saat ini berjalan dengan sangat cepat, meliputi software maupun hardware yang terdapat dalam pesawat CT Scan. Pesawat CT Scan saat ini terdapat empat generasi, namun yang saat ini sering digunakan adalah pesawat $C T$ Scan generasi ketiga dengan teknologi single slice dan multi slice. Multi slice CT Scan adalah pesawat $C T$ Scan yang menggabungkan dua bahkan lebih detektor array yang berdampingan sehingga dapat menghasilkan dua atau lebih gambaran secara stimulan atau dalam waktu bersamaan (Samsun,2008). Saat ini pengembangan teknologi CT Scan pada khususnya software tidak hanya berfokus pada aplikasi post processing saja, namun saat ini juga terus dikembangkan aplikasi untuk mengurangi jumlah dosis radiasi yang diterima oleh pasien salah satunya adalah aplikasi automatic exposure control (AEC).

Menurut Söderberg (2013), salah satu teknik efektif yang terdapat dalam CT Scan untuk menurunkan jumlah dosis radiasi yang diterima adalah penggunaan automatic exposure control (AEC). AEC digunakan untuk memastikan kualitas citra yang dihasilkan sama untuk setiap bagian tubuh dengan dosis serendah mungkin. Sistem ini bekerja dengan modulasi faktor eksposi tabung otomatis yang mengikuti sesuai ukuran pasien dengan mengikuti sumbu $\mathrm{z}$ tubuh sehingga atenuasi berubah secara real time. Sistem AEC yang terdapat pada pesawat Siemens disebut Care Dose 4D. Sebagai alat untuk menunjang penegakan diagnosa $C T$ Scan diharapkan dapat memberikan gambaran yang informatif, terutama informasi anatomis yang dikehendaki. Namun kadangkala ditemui adanya image noise yang mengganggu citra yang dihasilkan. Banyak faktor yang berkontribusi terhadap terjadinya image noise di CT Scan, diantaranya adalah penyerapan foton rendah energi, kehilangan data selama akuisisi, masalah software dan hardware, dan exposure yang kurang tepat (Al-Ameen, 2014).

Penelitian yang dilakukan oleh Sookpeng (2014), dengan membandingkan antara penggunaan aplikasi Care Dose $4 D$ dan Non Care Dose 4D pada pesawat CT Scan Siemens, didapatkan hasil variasi image noise dengan penggunaan aplikasi Care Dose $4 \mathrm{D}$ dibandingkan faktor eksposi tabung tetap adalah mengalami peningkatan sebesar $17 \%-18 \%$. Saat ini pencitraan $C T$ Scan lebih sering dilakukan, mengingat pasien bisa mendapatkan keuntungan diagnosis lebih cepat dan lebih akurat didapatkan sehingga informasi anatomi dapat 
digunakan dengan tepat untuk merencanakan prosedur terapi. Namun, terlepas dari kontribusi yang luar biasa dari CT untuk kesehatan, perhatian juga harus diberikan kepada risiko kesehatan yang sangat kecil yang terkait dengan dosis radiasi pengion yang diterima oleh tubuh pasien selama pemeriksaan CT (Mc Collough, 2009).

Dosis radiasi dari CT Scan harus dijaga serendah mungkin dan saat ini ada beberapa metode yang tersedia untuk mengoptimalkan dan meminimalkan dosis radiasi yang diserap di CT Scan. CTDIvol (Computed Tomography Dose Index Volume) adalah indikator dosis yang paling umum digunakan. Tampilan informasi ini pada CT Scanner modern diwajibkan oleh peraturan Uni Eropa, tetapi di luar Uni Eropa beberapa produsen menyediakan informasi CTDIvol hanya ketika kapan dibutuhkan oleh pengguna, hal tersebut dikemukakan oleh Chang Hyun Lee (2008). Menurut Söderberg (2013), terdapat sejumlah manfaat yang didapatkan ketika menggunakan system Care Dose 4D, salah satu manfaat adalah memiliki potensi untuk pengurangan dosis, seperti penelitian yang telah dilakukan pada Anthropomorphic chest phantom $P B U-X-21$. Untuk Anthropomorphic chest phantom $P B U-X-21$, besarnya pengurangan dosis yang diserap adalah cukup besar yakni mulai dari $35 \%$ hingga $60 \%$ dibandingkan dengan tidak menggunakan aplikasi Care Dose $4 D$.

Berdasarkan pengalaman penulis pada saat melakukan pemeriksaan CT Scan di Rumah Sakit, penulis sering menjumpai penggunaan Care Dose $4 D$ tidak digunakan dikarenakan menilai aplikasi tersebut cukup dikhawatirkan dapat meningkatkan nilai image noise pada citra CT Scan. Penulis telah melihat dalam SPO (Standar Prosedur Operasional) terkait dengan teknik pemeriksaan CT Scan, penggunaan aplikasi Care Dose $4 D$ belum terdapat didalamnya sehingga terdapat perbedaan teknik yang dilakukan antar operator $C T$ Scan. Untuk menghasilkan citra CT Scan yang memiliki standar yang sama antar operator $C T$ Scan seharusnya penggunaan aplikasi Care Dose 4D dapat dimasukkan kedalam SPO pemeriksaan.

SPO pemeriksaan merupakan pedoman bagi seorang operator CT Scan untuk melakukan sebuah pemeriksaan terkait prosedur pemeriksaan, teknik pengambilan citra, post processing, hingga filming. Dengan adanya SPO diharapkan hasil radiograf antar operator CT Scan memiliki standar yang sama untuk dilakukan penilaian oleh seorang radiolog. Diharapkan dengan adanya suatu penelitian yang berkaitan dengan penggunaan aplikasi Care Dose 4D dapat memiliki konstribusi saran untuk dapat dijadikan suatu usulan dalam perubahan SPO pemeriksaan CT Scan.

Tujuan dilakukan penelitian ini untuk mengetahui perbedaan image noise, dan perbedaan dosis radiasi (CTDI) penggunaan aplikasi Care Dose $4 D$ dan non Care Dose $4 D$ pada pesawat MSCT Siemens.

\section{METODE}

Penelitian ini adalah penelitian kuantitatif dengan pendekatan eksperimen yang diujikan pada empat macam ukuran water phantom. Variabel independent dalam penelitian ini adalah Care Dose 4D dan Non Care Dose 4D, sedangkan variabel dependent adalah image noise dan dosis radiasi, sebagai variabel terkontrol adalah FoV, water phantom, kernel, dan slice thickness. Penelitian ini dilakukan pada bulan April sampai Mei 2016 di Instalasi Radiologi Rumah Sakit Mardi Rahayu Kudus.

Penelitian ini dilakukan dengan melakukan pengambilan citra CT-Scan dengan menggunakan Aplikasi CareDose $4 D$ dan non CareDose4D pada Pesawat CT-Scan dengan merk Siemens Somatom Perspective di Instalasi Radiologi RS Mardi Rahayu Kudus. Protokol pemeriksaan yang digunakan disesuaikan dengan protokol pemeriksaan Nasopharing yang sehari hari dilaksanakan pada pasien dewasa dan anak-anak. Penempatan water Phantom berada diatas meja pemeriksaan CT Scan. pengaturan empat water phantom dengan urutan variasi diameter adalah $(30 \mathrm{~cm}-24 \mathrm{~cm}-18 \mathrm{~cm}-40 \mathrm{~cm})$ hal ini dimaksudkan untuk memperoleh simulasi bentuk tubuh yang bervariasi seperti pada CT Scan organ nashoparing $30 \mathrm{~cm} 24$ $\mathrm{cm} 18 \mathrm{~cm}$ dan $40 \mathrm{~cm}$

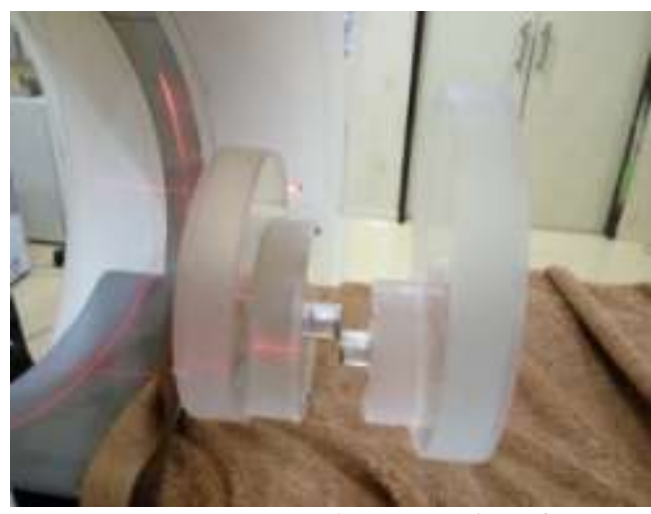

Gambar 1. Penempatan Water Phantom pada meja pemeriksaan

Analisa data akan dilaksanakan dengan dua pendekatan, yakni secara deskriptif dan secara statistik. Data yang telah terkumpul akan dibuat dalam bentuk tabel pada masing masing tahapan penelitian. Pada analisis data secara deskriptif akan diambil kesimpulan dari data yang ada dalam tabel, sedangkan analis data yang dilakukan dengan uji statistik, akan diuji normalitas data terlebih dahulu, menggunakan uji one sample Kolmogorov-Smirnov Test. Setelah data dinyatakan normal dengan nilai Sig < 0,05, dan dilanjutkan dengan uji Paired T-Test Samples untuk melakukan pengujian terhadap hipotesa dan melihat tingkat perbedaan informasi citra, karena melakukan pengujian pada satu sampel dengan dua perlakuan yang berbeda. Pada analisis statistik ini ditetapkan tingkat kepercayaan (level of Significance) dengan nilai $\alpha=0,05$. Hasil yang akan dinilai Ha ditolak apabila $\mathrm{p}$ value >0,05, yang berarti tidak ada perbedaan antara penggunaan aplikasi Care Dose 4D dan tanpa menggunakan aplikasi Care Dose 4D, namun jika $\mathrm{p}$ value $<0,05$ berarti terdapat perbedaan antara penggunaan aplikasi Care Dose 4D dan tanpa menggunakan aplikasi Care Dose 4D. Tujuannya untuk membandingkan nilai image noise apakah mempunyai rata-rata sama atau berbeda secara signifikan (Santoso, 2001). Hipotesis dalam penelitian ini sebagai berikut : 
$\mathrm{H}_{0}=$ Tidak ada perbedaan image noise dan CTDIvol terhadap penggunaan Care Dose 4D

$\mathrm{Ha}=$ Ada perbedaan image noise dan CTDIvol terhadap penggunaan Care Dose 4D

\section{HASIL}

Penelitian dilakukan terhadap empat macam ukuran phantom dengan protokol pemeriksaan Nasopharing untuk dewasa dan untuk anak-anak. Hasil citra Scanogram seperti yang ditunjukkan oleh gambar 2 .

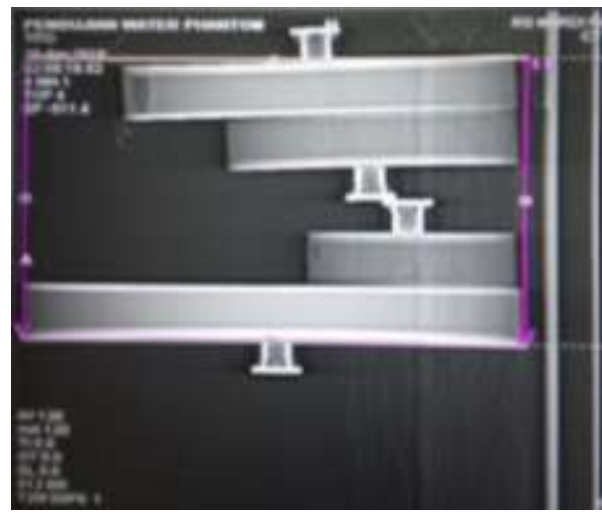

Gambar 2. Scanogram pengujian

Pada protokol pemeriksaan Nasopharing untuk anak anak, digunakan parameter pemeriksaan yang digunakan adalah sebagai berikut :
Kv $\quad: 130$
mAs : ref mAs 130 (Care Dose $4 D)$
eff mAs 130 (Non Care Dose 4D)
Pitch : 0,6
Slice Width $\quad: 5 \mathrm{~mm}$
Slice Collimation: 32 x 0,6 mm
FoV : $406 \mathrm{~mm}$
Rotation Time : $1,0 \mathrm{~s}$
Scan Time : 26,77 s

Didapatkan hasil pencatatan eff mAs seperti pada Tabel 1.

Tabel 1. Hasil pencatatan mAs pada penggunaan Care Dose $4 D$ dan Non Care Dose $4 D$ pada masing masing ukuran water phantom 130

\begin{tabular}{|c|c|c|}
\hline Water Phantom & $\begin{array}{l}\text { Non Care } \\
\text { Dose } 4 D\end{array}$ & Care Dose $4 D$ \\
\hline $18 \mathrm{~cm}$ & Eff mAs : 130 & Eff mAs: 58 \\
\hline $24 \mathrm{~cm}$ & Eff mAs : 130 & Eff mAs: 116 \\
\hline $30 \mathrm{~cm}$ & Eff mAs : 130 & Eff mAs: 215 \\
\hline $40 \mathrm{~cm}$ & Eff mAs : 130 & Eff mAs: 385 \\
\hline
\end{tabular}

Untuk Scanning dengan menggunakan protokol pemeriksaan nasopharing anak anak, pada scanning pertama dilakukan tanpa mengaktifkan aplikasi Care Dose 4D, sehingga keluaran mAs akan tetap pada 130 mAs, sedangkan pada scanning kedua dilakukan pengaktifan aplikasi Care
Dose $4 D$ sehingga mAs yang dikeluarkan akan mengikuti dari ketebalan objek yang bervariasi antara $58 \mathrm{mAs}$ hingga tertinggi $385 \mathrm{mAs}$. Dari semua citra hasil pengujian antara penggunaan aplikasi Care Dose $4 D$ dan Non Care Dose $4 D$ pada gambar, dilakukan pengukuran nilai image noise pada masing masing ukuran phantom dengan menggunakan fasilitas software (ROI) pada dua belas titik,yaitu empat pada tepi dan delapan pada pertengahan citra. Hasil Citra dengan menggunakan protokol anak anak pada gambar 3 dan 4 .

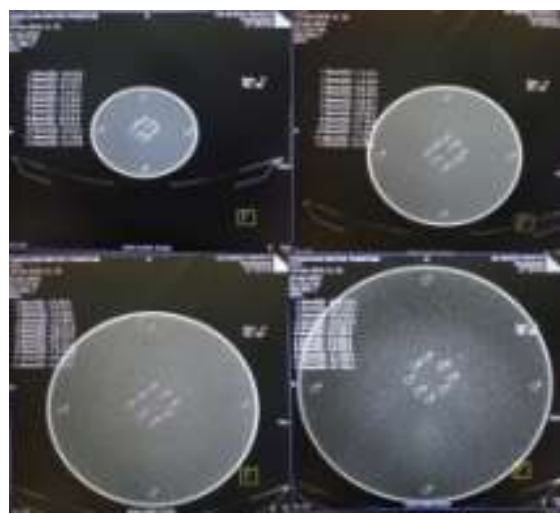

Gambar 3. Citra $130 \mathrm{kV} 130 \mathrm{mAs}$ Non care Dose 4D

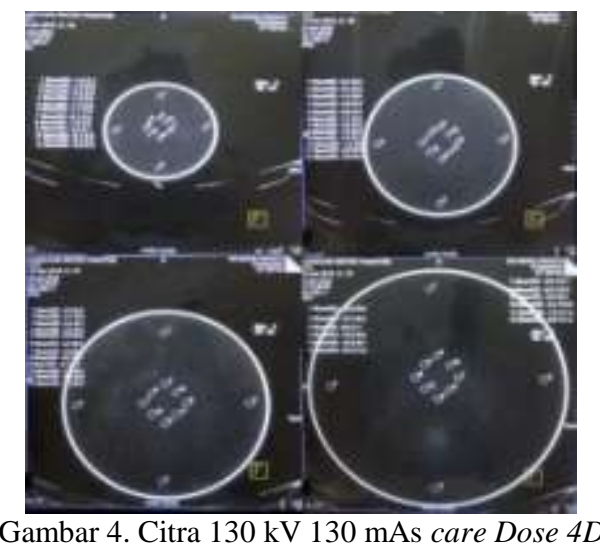

Tabel 2. Hasil pengukuran Image Noise pada Non Care Dose 4D pada water phantom $130 \mathrm{kV}$ dan $130 \mathrm{mAs}$.

\begin{tabular}{|c|c|c|c|c|}
\hline \multirow{2}{*}{ Titik Pengukuran } & \multicolumn{4}{|c|}{ Diameter Water Phantom } \\
\hline & $18 \mathrm{CM}$ & $24 \mathrm{CM}$ & $30 \mathrm{CM}$ & $40 \mathrm{CM}$ \\
\hline 1. & 3,0 & 4,3 & 6,9 & 13,3 \\
\hline 2. & 2,9 & 3,9 & 7,0 & 15,1 \\
\hline 3. & 3,2 & 3,8 & 8,9 & 13,5 \\
\hline 4. & 3,1 & 5,3 & 8,9 & 14,5 \\
\hline 5. & 3,3 & 5,1 & 11,3 & 22,3 \\
\hline 6. & 3,0 & 6,2 & 11,9 & 24,6 \\
\hline 7. & 3,6 & 6,2 & 12,4 & 23,2 \\
\hline 8. & 3,2 & 6,2 & 11,1 & 22,5 \\
\hline 9. & 3,2 & 7,8 & 13,3 & 22,6 \\
\hline 10. & 3,1 & 6,8 & 11,8 & 24,3 \\
\hline 11. & 3,9 & 6,5 & 10,7 & 24,5 \\
\hline 12. & 3,6 & 5,8 & 12,1 & 24,4 \\
\hline $\begin{array}{c}\text { Rata- rata setiap } \\
\text { diameter water } \\
\text { phantom }\end{array}$ & 3,3 & 5,7 & 10,5 & 20,4 \\
\hline $\begin{array}{c}\text { Rata-rata } \\
\text { keseluruhan }\end{array}$ & \multicolumn{4}{|c|}{9,96} \\
\hline
\end{tabular}


Pada scanning pertama dilakukan tanpa mengaktifkan aplikasi Care Dose 4D. Hasil yang tertera dalam tabel 2 didapatkan nilai rata-rata hasil image noise adalah 3,3 pada water phantom ukuran $18 \mathrm{~cm}, 5,7$ pada ukuran $24 \mathrm{~cm}, 10,5$ pada ukuran $30 \mathrm{~cm}$, dan 20,4 pada water phantom yang berukuran $40 \mathrm{~cm}$ dengan rata-rata nilai Image Noise keseluruhan adalah 9,96. Sedangkan pada scanning kedua dilakukan dengan mengaktifkan aplikasi Care Dose 4D. Hasil yang tertera dalam tabel 3 didapatkan rata-rata hasil image noise 3,7 pada water phantom berukuran $18 \mathrm{~cm}, 4,6$ pada ukuran $24 \mathrm{~cm}, 7,7$ pada ukuran $30 \mathrm{~cm}$, dan 9,1 pada water phantom yang berukuran $40 \mathrm{~cm}$, dengan rata -rata nilaiImage Noise keseluruhan adalah 6,30.

Tabel 3. Hasil pengukuran Image Noise penggunaan Care Dose 4D pada water phantom $130 \mathrm{kV}$ dan Reff. $130 \mathrm{mAs}$.

\begin{tabular}{|c|c|c|c|c|}
\hline \multirow{4}{*}{ Titik Pengukuran } & \multicolumn{4}{|c|}{ Diameter Water Phantom } \\
\hline & $18 \mathrm{CM} /$ & $24 \mathrm{CM} /$ & $30 \mathrm{CM} /$ & $40 \mathrm{CM} /$ \\
\hline & Eff. 58 & Eff.116 & Eff. 215 & Eff.385 \\
\hline & mAs & mAs & $\mathrm{mAs}$ & mAs \\
\hline 1. & 3,4 & 3,5 & 5,6 & 5,9 \\
\hline 2. & 3,4 & 3,5 & 5,5 & 6,2 \\
\hline 3. & 3,5 & 3,6 & 6,1 & 7,1 \\
\hline 4. & 2,4 & 3,5 & 5,0 & 5,5 \\
\hline 5. & 4,4 & 4,5 & 9,5 & 9,7 \\
\hline 6. & 3,8 & 4,0 & 8,5 & 11,9 \\
\hline 7. & 4,1 & 5,0 & 8,6 & 10,1 \\
\hline 8. & 3,8 & 5,6 & 9,1 & 10,3 \\
\hline 9. & 3,8 & 5,3 & 8,1 & 9,5 \\
\hline 10. & 4,3 & 5,9 & 8,4 & 10,0 \\
\hline 11. & 4,1 & 5,5 & 8,8 & 11,4 \\
\hline 12. & 3,3 & 5,4 & 9,0 & 11,2 \\
\hline $\begin{array}{l}\text { Rata- rata setiap } \\
\text { diameter water } \\
\text { phantom }\end{array}$ & 3,7 & 4,6 & 7,7 & 9,1 \\
\hline $\begin{array}{c}\text { Rata-rata } \\
\text { keseluruhan }\end{array}$ & \multicolumn{4}{|c|}{6,30} \\
\hline
\end{tabular}

Tabel 4. Hasil pencatatan mAs pada penggunaan Care Dose $4 D$ dan Non Care Dose $4 D$ pada masing masing ukuran water phantom 130

\begin{tabular}{ccc} 
& $k$ N dan $220 \mathrm{mAs}$ \\
\hline Water Phantom & Non Care Dose $4 D$ & Care Dose $4 D$ \\
\hline $18 \mathrm{~cm}$ & Eff mAs : 220 & Eff mAs : 70 \\
$24 \mathrm{~cm}$ & Eff mAs : 220 & Eff mAs: 96 \\
$30 \mathrm{~cm}$ & Eff mAs : 220 & Eff mAs: 221 \\
$40 \mathrm{~cm}$ & Eff $m A s: 220$ & Eff mAs: 314 \\
\hline
\end{tabular}

Dari hasil tersebut, terlihat bahwa nilai rata-rata secara keseluruhan Image Noise tanpa menggunakan Care Dose $4 D$ lebih tinggi nilainya dibandingkan dengan menggunakan aplikasi Care Dose 4D.

Pada protokol pemeriksaan Nasopharing untuk dewasa, digunakan parameter pemeriksaan yang digunakan adalah sebagai berikut :
$\mathrm{kV}$
$: 130$
mAs
: ref mAs 220 (Care Dose 4D)
eff mAs 220 (Non Care Dose 4D)
Pitch

$$
\text { : } 0,6
$$

Slice Width $\quad: 5 \mathrm{~mm}$

Slice Collimation : 64 x 0,6 mm

FoV : :406 mm

Rotation Time : :0,6 s

Scan Time $\quad: 8,47 \mathrm{~s}$

Untuk Scanning dengan menggunakan protokol pemeriksaan nasopharing Dewasa, pada scanning pertama dilakukan tanpa mengaktifkan aplikasi Care Dose 4D, sehingga keluaran mAs akan tetap pada $120 \mathrm{mAs}$, sedangkan pada scanning kedua dilakukan pengaktifan aplikasi Care Dose $4 D$ sehingga mAs yang dikeluarkan akan mengikuti dari ketebalan objek yang bervariasi antara $70 \mathrm{mAs}$ hingga tertinggi 314 mAs. Dari semua citra hasil pengujian antara penggunaan aplikasi Care Dose $4 D$ dan Non Care Dose 4D pada citra, dilakukan pengukuran nilai image noise pada masing masing ukuran phantom dengan menggunakan fasilitas software (ROI) pada dua belas titik, yaitu empat pada tepi dan delapan pada pertengahan citra.
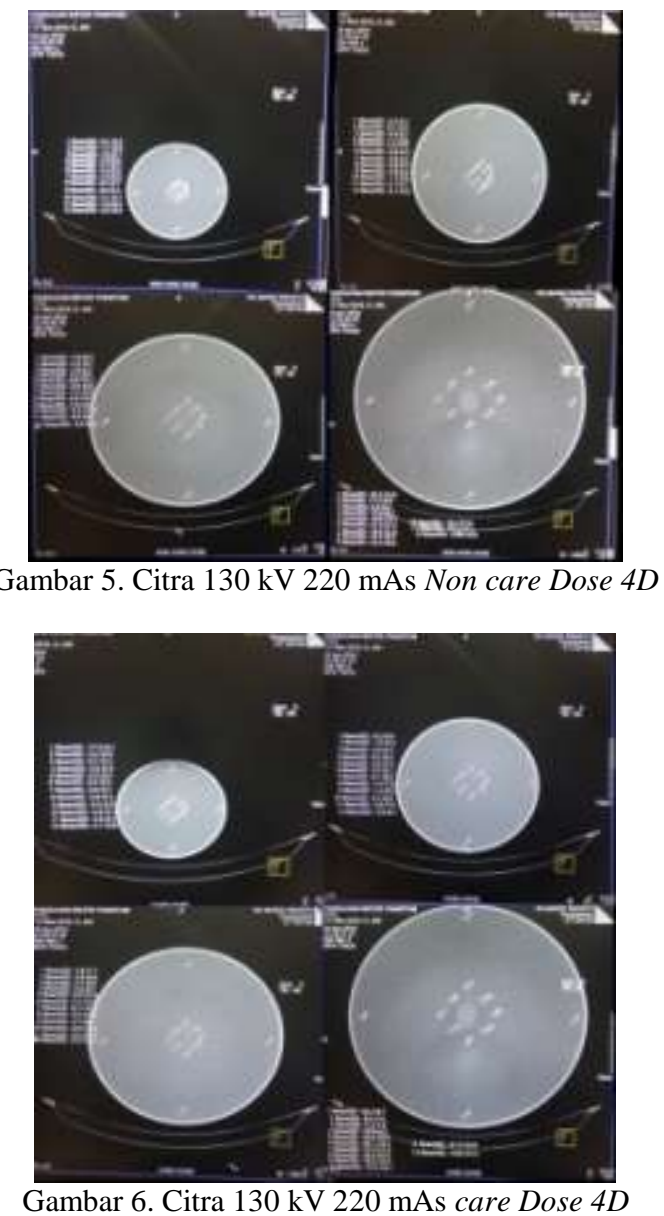

Pada scanning pertama dilakukan tanpa mengaktifkan aplikasi Care Dose 4D. Hasil yang tertera dalam tabel 5 Didapatkan nilai rata-rata hasil image noise adalah 2,8 pada water phantom ukuran $18 \mathrm{~cm}, 4,5$ pada ukuran $24 \mathrm{~cm}, 8,5$ pada ukuran $30 \mathrm{~cm}$, dan 15,8 pada water phantom yang berukuran $40 \mathrm{~cm}$ dengan rata-rata nilai Image Noise keseluruhan adalah 7,89 . 
Tabel 5. Hasil pengukuran Image Noise pada penggunaan Non Care Dose $4 \mathrm{D}$ pada water phantom $130 \mathrm{kV}$ dan $220 \mathrm{mAs}$.

\begin{tabular}{|c|c|c|c|c|}
\hline \multirow{2}{*}{ Titik Pengukuran } & \multicolumn{4}{|c|}{ Diameter Water Phantom } \\
\hline & $18 \mathrm{CM}$ & $24 \mathrm{CM}$ & $30 \mathrm{CM}$ & $40 \mathrm{CM}$ \\
\hline 1. & 1. & 2,0 & 3,1 & 5,0 \\
\hline 2. & 2. & 2,6 & 4,0 & 5,7 \\
\hline 3. & 3. & 2,1 & 3,1 & 4,7 \\
\hline 4. & 4. & 2,4 & 3,4 & 6,5 \\
\hline 5. & 5. & 2,7 & 5,8 & 10,1 \\
\hline 6. & 6. & 2,5 & 4,0 & 9,8 \\
\hline 7. & 7. & 3,5 & 5,3 & 10,3 \\
\hline 8. & 8. & 2,7 & 5,0 & 10,0 \\
\hline 9. & 9. & 2,4 & 4,4 & 10,1 \\
\hline 10. & 10. & 3,7 & 5,8 & 11,3 \\
\hline 11. & 11. & 3,0 & 5,7 & 9,2 \\
\hline 12. & 12. & 3,6 & 4,6 & 9,5 \\
\hline $\begin{array}{l}\text { Rata- rata setiap } \\
\text { diameter water } \\
\text { phantom }\end{array}$ & 2,8 & 4,5 & 8,5 & 15,8 \\
\hline $\begin{array}{c}\text { Rata-rata } \\
\text { keseluruhan }\end{array}$ & \multicolumn{4}{|c|}{7,89} \\
\hline
\end{tabular}

Tabel 6. Hasil pengukuran Image Noise penggunaan Care Dose 4D pada water phantom $130 \mathrm{kV}$ dan Reff. $220 \mathrm{mAs}$.

\begin{tabular}{|c|c|c|c|c|}
\hline \multirow[b]{2}{*}{ Titik Pengukuran } & \multicolumn{4}{|c|}{ Diameter Water Phantom } \\
\hline & $\begin{array}{c}18 \mathrm{CM} / \\
\text { Eff. } 70 \\
\text { mAs }\end{array}$ & $\begin{array}{l}24 \mathrm{CM} / \\
\text { Eff.96 } \\
\text { mAs }\end{array}$ & $\begin{array}{c}30 \mathrm{CM} / \\
\text { Eff. } 221 \\
\mathrm{mAs}\end{array}$ & $\begin{array}{c}40 \mathrm{CM} / \\
\text { Eff. } 314 \\
\mathrm{mAs}\end{array}$ \\
\hline 1. & 3,1 & 5,0 & 7,7 & 8,7 \\
\hline 2. & 2,8 & 4,4 & 6,8 & 7,0 \\
\hline 3. & 2,2 & 4,3 & 6,6 & 7,6 \\
\hline 4. & 2,5 & 5,4 & 6,7 & 6,2 \\
\hline 5. & 3,4 & 7,5 & 13,5 & 13,6 \\
\hline 6. & 3,5 & 5,1 & 12,5 & 16,2 \\
\hline 7. & 2,7 & 6,9 & 12,9 & 17,0 \\
\hline 8. & 3,3 & 7,6 & 13,2 & 15,3 \\
\hline 9. & 2,6 & 6,2 & 9,6 & 15,0 \\
\hline 10. & 3,1 & 8,5 & 10,9 & 16,1 \\
\hline 11. & 3,1 & 7,0 & 11,9 & 15,9 \\
\hline 12. & 3,6 & 8,1 & 13,4 & 14,2 \\
\hline $\begin{array}{l}\text { Rata- rata setiap } \\
\text { diameter water } \\
\text { phantom }\end{array}$ & 3,0 & 6,3 & 10,5 & 12,7 \\
\hline $\begin{array}{l}\text { Rata-rata } \\
\text { keseluruhan }\end{array}$ & \multicolumn{4}{|c|}{8,13} \\
\hline
\end{tabular}

Pada scanning kedua dilakukan dengan mengaktifkan aplikasi Care Dose 4D. Pada tabel 6 didapatkan rata-rata hasil image noise 3,0 pada water phantom ukuran $18 \mathrm{~cm}, 6,3$ pada ukuran $24 \mathrm{~cm}, 10,5$ pada ukuran $30 \mathrm{~cm}$, dan 12,7 pada water phantom yang berukuran $40 \mathrm{~cm}$, dengan rata -rata nilai Image Noise keseluruhan adalah 8,13. Dari hasil tersebut, terlihat bahwa nilai rata-rata secara keseluruhan Image Noise dengan menggunakan Care Dose $4 D$ lebih tinggi nilainya dibandingkan tanpa menggunakan aplikasi Care Dose 4D walaupun selisihnya sangat kecil. Berdasarkan hasil pengukuran nilai Image Noise, dilakukan uji statistik dengan menggunakan aplikasi pengolah data statistik IBM SPSS Statistics versi 20 untuk dilakukan analisis data yang sudah diperoleh. Untuk menguji distribusi data normal atau tidak, data tersebut diuji menggunakan One-Sample KolmogorovSmirnov Test, karena data berdistribusi normal maka dilanjutkan dengan uji Paired T-Test Samples.

Protokol Nasopharing Anak-anak :

Tabel 7. Hasil One-Sample Kolmogorov-Smirnov Test Pengukuran Nilai Image Noise Pada Care Dose 4D dan Non Care Dose 4D 130 $\mathrm{kV}$ dan $130 \mathrm{mAs}$.

\begin{tabular}{ccc}
\hline Variabel & $\rho$ value & Makna \\
\hline Non Care Dose $4 D$ &, 083 & Berdistribusi Normal \\
Care Dose $4 D$ &, 165 & Berdistribusi Normal \\
\hline
\end{tabular}

Data telah melalui proses uji normalitas data yang telah dinyatakan berdistribusi normal peneliti melanjutkan dengan menggunakan uji analisis Paired T-Test Samples Test. Uji tersebut dimaksudkan untuk menganalisis adanya perbedaan data yang berpasangan, yaitu satu sampel dengan dua perlakuan yang berbeda. Hasil uji Paired T-Test Samples Test sebagai berikut :

Tabel 8. Hasil uji Paired T-Test Samples Test Pengukuran Nilai Image Noise Pada Care Dose 4D dan Non Care Dose 4D $130 \mathrm{kV}$ dan $130 \mathrm{mAs}$

\begin{tabular}{cccc}
\hline Variabel & $\rho$ value & T Hitung & Makna \\
\hline $\begin{array}{c}\text { Non Care Dose 4D } \\
\text { Care Dose 4D }\end{array}$ &, 000 & 5,299 & Ada Perbedaan \\
\hline
\end{tabular}

Berdasarkan Uji statistik dengan uji Paired T-Test Samples Test diperoleh nilai significancy $\rho$ value $<0,05$ maka Ho ditolak dan ha diterima yang memiliki arti terdapat perbedaan yang signifikan nilai image noise antara penggunaan Care Dose 4D dan Non Care Dose 4D $130 \mathrm{kV}$ dan $130 \mathrm{mAs}$.

Protokol Nasopharing Dewasa :

Tabel 9. Hasil One-Sample Kolmogorov-Smirnov Test Pengukuran Nilai Image Noise Pada Care Dose 4D dan Non Care Dose 4D 130 $\mathrm{kV}$ dan $220 \mathrm{mAs}$.

\begin{tabular}{ccc}
\hline Variabel & $\rho$ value & Makna \\
\hline Non Care Dose $4 D$ &, 034 & Berdistribusi Normal \\
Care Dose $4 D$ &, 287 & Berdistribusi Normal \\
\hline
\end{tabular}

Data telah melalui proses uji normalitas data yang telah dinyatakan berdistribusi normal peneliti melanjutkan dengan menggunakan uji analisis Paired T-Test Samples Test. Uji tersebut dimaksudkan untuk menganalisis adanya perbedaan data yang berpasangan, yaitu satu sampel dengan dua perlakuan yang berbeda. Hasil uji Paired T-Test Samples Test sebagai berikut :

Tabel 10. Hasil uji Paired T-Test Samples Test Pengukuran Nilai Image Noise Pada Care Dose 4D dan Non Care Dose $4 D 130 \mathrm{kV}$ dan $220 \mathrm{mAs}$.

\begin{tabular}{cccc}
\hline Variabel & $\rho$ value & T Hitung & Makna \\
\hline $\begin{array}{c}\text { Non Care Dose } 4 D \\
\text { Care Dose } 4 D\end{array}$ &, 481 &,- 710 & $\begin{array}{c}\text { Tidak Ada } \\
\text { Perbedaan }\end{array}$ \\
\hline
\end{tabular}


Berdasarkan Uji statistik dengan uji Paired T-Test Samples Test diperoleh nilai significancy $\rho$ value $>0,05$ maka Ho diterima dan ha ditolak yang memiliki arti tidak ada perbedaan yang signifikan nilai imaghe noise antara penggunaan Care Dose 4D dan Non Care Dose 4D $130 \mathrm{kV}$ dan 220 mAs.

Dalam penelitian ini penulis mendapatkan nilai dosis radiasi dengan melakukan scanning menggunakan water phantom berukuran $30 \mathrm{~cm}-24 \mathrm{~cm}-18 \mathrm{~cm}-40 \mathrm{~cm}$ yang diatur berjajar. Tujuan penempatan water phantom dengan urutan seperti tersebut adalah untuk mendapatkan gambaran perbedaan ukuran yang terdapat dalam nasopharing. Penelitian ini menggunakan dua protokol pemeriksaan organ nasopharing dan menggunakan dua perlakuan yang berbeda yakni dengan menggunakan aplikasi Care Dose $4 D$ dan non Care Dose 4D.

Protokol Nasopharing Anak-anak. Untuk Scanning dengan protokol pemeriksaan nasopharing anak anak, hasil pengujian antara penggunaan aplikasi Care Dose 4D dan Non Care Dose 4D didapatkan hasil CTDIvol pada scanning tanpa menggunakan aplikasi Care Dose 4D adalah 15,09 mGy, sedangkan dengan mengaktifkan aplikasi Care Dose $4 D$ CTDIvol yang dihasilkan pada scanning tersebut adalah 20,12 mGy. Sehingga hasil yang didapatkan adalah pada penggunaan Care Dose 4D terjadi peningkatan nilai CTDIvol yang cukup besar dibandingkan tanpa menggunakan aplikasi Care Dose 4D.

Protokol Nasopharing Dewasa. Untuk Scanning protokol pemeriksaan nasopharing dewasa, dari hasil pengujian antara penggunaan aplikasi Care Dose $4 D$ dan Non Care Dose $4 D$ didapatkan hasil CTDIvol pada scanning tanpa menggunakan aplikasi Care Dose 4D adalah 24,24 mGy, sedangkan dengan menggunakan aplikasi Care Dose 4D CTDIvol yang dihasilkan pada scanning tersebut adalah 21,60 mGy. Dapat diketahui jika tanpa penggunaan Care Dose $4 D$ terjadi peningkatan nilai CTDIvol dibandingkan dengan mengaktifkan aplikasi Care Dose 4D.

\section{PEMBAHASAN}

Perbedaan image noise terhadap penggunaan aplikasi Care Dose 4D dan non Care Dose $4 D$ pada pesawat MSCT Siemens

Berdasarkan hasil analisa deskriptif dapat dilihat bahwa pada penggunaan protokol nasopharing anak anak dengan menggunakan aplikasi Care Dose $4 D$ dapat menurunkan nilai image noise. Namun pada penggunaan protokol pemeriksaan di dewasa hasil image noise hampir sama, hanya sedikit selisih nilai image noise antara penggunaan Care Dose $4 \mathrm{D}$ dan Non Care Dose 4D.

Pada penggunaan aplikasi Care Dose 4D hasil keluaran mAs pada penggunaan protokol anak-anak dan dewasa mempunyai nilai yang hampir sama, walaupun nilai reff $\mathrm{mAs}$ berbeda, hal ini dikarenakan pada aplikasi Care Dose $4 D$ menggunakan prinsip kerja dari AEC (Automatic Exposured Control) yang bekerja dengan cara mengikuti ketebalan objek pada water phantom, dan hal ini sesuai dengan pernyataan oleh Sookpeng (2014), Sistem AEC Siemens atau lebih dikenal dengan "Care Dose 4D" yaitu gabungan teknik modulasi (xyz). Ini menggabungkan tiga metode adaptasi yang berbeda untuk mengoptimalkan kualitas gambar, adaptasi otomatis arus tabung untuk menyesuaikan ukuran pasien, dengan menggunakan atenuasi dari sumbu memanjang dari pasien (Z Axis) dan akan langsung diatur melalui program untuk setiap rotasi tabung (angular modulasi).

Untuk dapat menentukan apakah terdapat perbedaan atau tidak dalam penggunaan aplikasi Care Dose 4D dan Non Care Dose $4 D$ maka dilakukan uji statistik, sehingga dihasilkan penarikan kesimpulan yang tepat. Uji statistik yang digunakan adalah Paired T-Test, untuk hasil uji statistik dapat dijelaskan sebagai berikut :

Pada protokol anak anak menunjukkan angka $\rho$ value sebesar 0,000 dan $\mathrm{T}$ Hitung 5,299. Hasil tersebut dapat memiliki arti Ho ditolak dan Ha diterima yang dapat disimpulkan bahwa terdapat perbedaan image noise antara penggunaan Care Dose 4D dan Non Care Dose 4D. Aplikasi Care Dose $4 D$ memiliki keuntungan menurunkan angka image noise, sehingga ketika klinisi menghendaki hasil citra yang baik dengan image noise yang kecil menggunakan aplikasi Care Dose $4 D$ merupakan suatu pilihan yang tepat.

Pada protokol pemeriksaan Nasopharing dewasa angka $\rho$ value sebesar 0,481 dan T Hitung -0,710. Hasil tersebut dapat memiliki arti Ho diterima dan $\mathrm{Ha}$ ditolak yang dapat disimpulkan bahwa tidak terdapat perbedaan image noise antara penggunaan Care Dose 4D dan Non Care Dose 4D. Dalam penggunaan protokol pemeriksaan Nasopharing dewasa penggunaan Aplikasi Care Dose 4D dan Non Care Dose $4 D$ tidak memiliki perbedaan hasil citra, sehingga penggunaan aplikasi Care Dose $4 \mathrm{D}$ oleh operator CT-Scan dapat diabaikan dalam hal hasil citra.

Penggunaan nilai reff $\mathrm{mAs}$ yang berbeda saat penggunaan Aplikasi Care Dose 4D pada pemilihan parameter mempengaruhi image noise yang dihasilkannya, hal ini sesuai dengan pernyataan Rego et al., (2007), yaitu Pemindai menentukan quality reference $m A s$ (QRM) untuk setiap protokol. Ini dinyatakan dalam mAs efektif dan digunakan untuk menentukan tingkat kualitas citra untuk pasien berukuran standar. Sebuah mAs efektif diperkirakan dan disesuaikan selama pemindaian berdasarkan pengukuran real time atenuasi pasien Care Dose $4 D$ otomatis menyesuaikan efektif mAs untuk perubahan atenuasi pasien dalam wilayah pemindaian berdasarkan data QRM. Pengguna dapat mengubah nilai quality reference $m A s$ (QRM) dan juga memodifikasi "kekuatan" dari tabung modulasi untuk menentukan tingkat penurunan tegangan dalam tabung untuk pasien kurus dan peningkatan untuk pasien yang lebih besar.

Berdasarkan hasil penelitian yang telah dilakukan analisa secara deskriptif, didapatkan nilai dosis radiasi dalam CTDIvol dengan satuan mGy. Pada protokol Nasopharing anak-anak dengan parameter $130 \mathrm{kV}, 130 \mathrm{mAs}$,dan $A c q$ Collimation 32 X 0,6 mm, didapatkan hasil CTDIvol pada pengaplikasian Care Dose 4D adalah 20,12 mGy, sedangkan jika tidak mengaktifkan aplikasi Care Dose $4 D$, dosis yang didapatkan adalah sebesar 15,09 mGy. 
Terjadi peningkatan yang cukup besar antara penggunaan Aplikasi Care Dose 4D dan Non Care Dose 4D. Penggunaan Aplikasi Care Dose $4 D$ pada parameter $130 \mathrm{kV}$, 130,dan mAs Acq Collimation 32 X 0,6 mm ternyata justru meningkatkan dosis yang diterima oleh pasien pada pencatatan CTDIvol sebesar 5,03 mGy. Hal tersebut bertentangan dengan pernyataan yang dikemukakan oleh Söderberg (2013), salah satu teknik efektif yang terdapat dalam CT Scan untuk menurunkan jumlah dosis radiasi yang diterima adalah penggunaan automatic exposure control (AEC).

Pada penelitian berikutnya penulis menggunakan protokol pemeriksaan Nasopharing Dewasa dengan parameter $130 \mathrm{kV}, 220 \mathrm{mAs}$,dan Acq Collimation 64 X 0,6 mm, didapatkan hasil CTDIvol adalah sebesar 24,24 mGy tanpa menggunakan aplikasi Care Dose 4D, dan dengan menggunakan aplikasi Care Dose $4 D$ sebesar 21,60 mGy. Penggunaan aplikasi Care Dose $4 D$ pada protokol dewasa, sangat berguna untuk menurunkan angka dosis radiasi yang diterima oleh pasien yang diketahui dengan nilai CTDIvol. Sehingga ketika operator CT-Scan memperhatikan masalah dosis yang diterima oleh pasien maka menggunakan aplikasi Care Dose $4 D$ menjadi pilihan yang tepat dan bijak untuk digunakan.

Menurut penulis penggunaan aplikasi Care Dose 4D pada anak anak digunakan situasional menurut kepentingan penegakan diagnosa yang semaksimal mungkin. Jika hasil yang diharapkan oleh dokter radiolog memiliki kualitas citra yang lebih baik maka penggunaan Care Dose 4D dapat diterapkan, namun jika tidak maka Care dose 4D dapat di non aktifkan dengan harapan dosis yang diterima oleh pasien anak anak dapat ditekan seminimal mungkin. Penggunaan aplikasi Care Dose 4D pada pasien dewasa dapat diaktifkan, dengan mempertimbangkan hasil yang didapat tidak berbeda dengan konvensional / non aplikasi Care Dose 4D. Justru penggunaan aplikasi Care Dose 4D dapat menurunkan dosis radiasi yang diterima oleh pasien.

Diharapkan dengan kita lebih memperhatikan mengenai dosis radiasi yang diterima oleh pasien maka bahaya radiasi yang mungkin dapat terjadi pada pasien dapat diminimalisir. Sehingga peran sebagai tenaga medis khususnya di bidang radiologi dapat maksimal dalam menjaga pasien dari risiko bahaya radiasi.

\section{SIMPULAN}

Hipotesis dalam penelitian ini adalah, $\mathrm{H}_{0}=$ Tidak ada perbedaan image noise dan CTDIvol terhadap penggunaan Care Dose 4D, dan $\mathrm{Ha}=$ Ada perbedaan image noise dan CTDIvol terhadap penggunaan Care Dose 4D Penggunaan aplikasi care dose 4D. Pada protokol Nasopharing anak anak dengan parameter $130 \mathrm{kV}$ dan $130 \mathrm{mAs}$, terdapat perbedaan hasil nilai image noise pada citra. Aplikasi care dose 4D dapat menurunkan nilai image noise dibandingkan dengan tidak menggunakan aplikasi Care Dose $4 D$ yaitu didapat hasil nilai rata-rata image noise non Care Dose $4 D$ adalah 9,96 sedangkan dengan aplikasi Care Dose 4D adalah 6,30. Pada protokol Nasopharing dewasa dengan parameter pemeriksaan
$130 \mathrm{kV}$ dan $220 \mathrm{mAs}$, penggunaan aplikasi Care Dose 4D menunjukkan tidak adanya perbedaan nilai image noise jika dibandingkan dengan teknik konvensional atau tanpa menggunakan aplikasi Care Dose $4 D$, pada penelitian didapat hasil nilai image noise tanpa aplikasi Care Dose 4D 7,89 dan dengan aplikasi Care Dose 4D 8,13. Pada penelitian ini terdapat keterbatasan yaitu terkait metode akuisisi citra dalam menggabungkan empat water phantom berbeda,dan teknik scanning dijadikan satu atau single scan dengan spiral scan. Hal tersebut dikawatirkan dapat menimbulkan scatters atau hamburan yang dapat mempengaruhi nilai image noise yang terdapat pada citra penelitian.

Aplikasi care dose 4D pada protokol Nasopharing anak anak justru meningkatkan nilai dosis radiasi dalam CTDIvol sebesar 5,03 mGy dibandingkan tanpa penggunaan aplikasi Care Dose 4D. Penggunaan Aplikasi Care Dose 4D pada protokol pemeriksaan Nasopharing dewasa menurunkan nilai dosis radiasi dalam CTDIvol 2,64 mGy dibandingkan tanpa penggunaan aplikasi Care Dose 4D.

\section{DAFTAR PUSTAKA}

Al-Ameen, Zohair. 2014. Attenuating noise from computed tomography medical images using a coefficients-driven total variation denoising algorithm. Universiti Teknologi Malaysia : Johor, Malaysia http://dl.acm.org/citation.cfm?id=2857411 diakses 10 Maret 2016

Bontrager, K.L. 2010. Text Book of Radiographic and Related Anatomy, seventh Edition. The CV Mosby : London.

Bushberg, Jerrold T, Siebert JA.PHD, Leidholdt EW.Jr, PHD, Boone JM,PHD. 2003. The Essential Physics of Medical Imaging, Second Edition. Lippincott Williams \& Wilkins.

Ferreira, T and Rasband W. 2011. The ImageJ User Guide - Version 1.44 U. S. National Institutes of Health : Bethesda, Maryland, USA.

Goldman, LW. 2007. Principles of CT: Radiation Dose and Image Quality Journal of Nuclear Medicine Technology Volume 35 Number 4, p213-225. Society of Nuclear Medicine.

Keat, N. 2005. CT scanner automatic exposure control systems. Medicines and Healthcare products Regulatory Agency (MHRA) evaluation report 05016.

Lee, Chang Hyun. 2008. Radiation Dose Modulation Techniques in the Multidetector CT Era: From Basics to Practice.

Mahesh, Mahadevappa. 2009. MDCT Physics The Basics Technology, Image Quality and Radiation Dose. Lippincott Williams a Wolters Kluwer business : Philadelphia.

McCollough, CH, Bruesewitz MR, Kofler J M. 2009. CT dose reduction and dose management tools: overview of available options. Radiographics 26: 503-512.

Rego, S.L, Yu L, Bruesewitz M R, Vrieze T J, Kofler J M and McCollough C H. 2007. Care Dose 4D CT Automatic exposure control (AEC): Physics principle and practical hints [online document] Available at http://mayoresearch.mayo.edu/mayo/research/ctcic/upload/rsna2007care-dose-4d.pdf, diakses tanggal 10 Januari 2016.

Samsun. 2008. Analisis pengukuran computed tomography dose index (CTDI) Untuk MSCT : Pengukuran Dengan Menggunakan TLD dan Bilik Ionisasi. FMIPA UI.

Seeram, Euclid, RT. 2001. Computed Tomography, Physical Principles, Clinical Applications, and Quality Control. WB Saunders Pennsylvania, USA

Sodeberg, Marcus Mikael Gunnarson. 2013. Automatic exposure control in computed tomography - an evaluation of systems from different manufacturers. Acta Radiologica : Washington. 
Sookpeng, Supawito. 2014. Investigation of CT dosimetry techniques for use in optimisation of Automatic Tube Current Modulation (ATCM) performance. University of Glasgow.

Suryaningsih. 2014. Analisis Pengaruh Faktor Eksposi terhadap Nilai Computed Tomography Dose Index (CTDI) pada Pesawat Computed Tomography CT) Scan. http://repository.unhas.ac.id/handle/ 123456789 /12106, diakses tanggal 11-03-2016.

The ImPACT Group. 2009. Buyer's Guided : Multi-Slice CT Scannes. St. George's Healthcare Trust, The ImPACT Group. Nhscep.useconnect.co.uk/ShowDocument.ashx?id=79\&i=true Diakses 14 Maret 2016 